OPEN ACCESS

Edited by:

Erxi Wu,

Baylor Scott and White Health,

United States

Reviewed by:

Andrew Liss,

Massachusetts General Hospital and Harvard Medical School,

United States

Jose Soto,

Baylor Scott and White Health,

United States

Ajay Dixit,

University of Minnesota Twin Cities, United States

*Correspondence: Jen Jen Yeh

jjyeh@med.unc.edu

Specialty section:

This article was submitted to Gastrointestinal Cancers: Hepato

Pancreatic Biliary Cancers,

a section of the journal

Frontiers in Oncology

Received: 31 July 2021 Accepted: 21 September 2021 Published: 06 October 2021

Citation:

Perez VM, Kearney JF and Yeh JJ (2021) The PDAC Extracellular Matrix:

A Review of the ECM Protein Composition, Tumor Cell Interaction, and Therapeutic Strategies.

Front. Oncol. 11:751311. doi: 10.3389/fonc.2021.751311

\section{The PDAC Extracellular Matrix: A Review of the ECM Protein Composition, Tumor Cell Interaction, and Therapeutic Strategies}

\author{
Vincent M. Perez ${ }^{1}$, Joseph F. Kearney ${ }^{1,2}$ and Jen Jen Yeh ${ }^{1,2,3^{*}}$ \\ 1 Lineberger Comprehensive Cancer Center, University of North Carolina at Chapel Hill, Chapel Hill, NC, United States, \\ 2 Department of Surgery, University of North Carolina at Chapel Hill, Chapel Hill, NC, United States, ${ }^{3}$ Department of \\ Pharmacology, University of North Carolina at Chapel Hill, Chapel Hill, NC, United States
}

Pancreatic ductal adenocarcinoma (PDAC) is notorious for a dense fibrotic stroma that is interlaced with a collagen-based extracellular matrix (ECM) that plays an important role in tumor biology. Traditionally thought to only provide a physical barrier from host responses and systemic chemotherapy, new studies have demonstrated that the ECM maintains biomechanical and biochemical properties of the tumor microenvironment (TME) and restrains tumor growth. Recent studies have shown that the ECM augments tumor stiffness, interstitial fluid pressure, cell-to-cell junctions, and microvascularity using a mix of biomechanical and biochemical signals to influence tumor fate for better or worse. In addition, PDAC tumors have been shown to use ECM-derived peptide fragments as a nutrient source in nutrient-poor conditions. While collagens are the most abundant proteins found in the ECM, several studies have identified growth factors, integrins, glycoproteins, and proteoglycans in the ECM. This review focuses on the dichotomous nature of the PDAC ECM, the types of collagens and other proteins found in the ECM, and therapeutic strategies targeting the PDAC ECM.

Keywords: pancreatic ductal adenocarcinoma, extracellular matrix, tumor microenvironment, proteome, cancer

\section{INTRODUCTION}

With a 5-year survival of $10 \%$, pancreatic ductal adenocarcinoma (PDAC) is the 3rd leading cause of cancer deaths in the United States and is projected to become the second leading cause of cancer deaths in the United States by $2030(1,2)$. Most patients have regional or distant spread at the time of diagnosis and are not eligible for a potentially curative operation (3). While advances have been made in the treatment of metastatic PDAC (4-6), most patients remain refractory to current regimens. Metastatic PDAC exhibits resistance to therapies like cytotoxic, radiation, and molecularly targeted therapies. A major factor thought to contribute to the treatment resistance of PDAC is its dense fibrotic stroma intertwined with the extracellular matrix (ECM), which together, provide a physical barrier of protection to the tumor cells and may also restrain tumor growth. 
Research has shown that the ECM plays several roles beyond acting as a barrier for tumor cells. The deposition of abundant ECM proteins is common among solid tumors like PDAC and is known as a desmoplastic reaction (7). This tumor microenvironment (TME) exerts mechanical and biochemical properties on tumor cells, modulates interstitial fluid pressure (8, 9), and reduces blood vessel density within tumors (8). Although evidence has shown that the ECM may be tumor promoting (10), recent research has demonstrated that the stroma and ECM may restrain tumor growth $(11,12)$. In addition, tumor metastases, the primary cause of patient mortality, have less stroma than primary tumors $(13,14)$. A major regulator of the ECM are cancer-associated fibroblasts (CAFs), which dominate the TME in abundance (15).

CAFs are thought to arise predominantly from pancreatic stellate cells (PSCs) and bone-marrow derived mesenchymal stem cells. Their formation has been shown to be secondary to tumor signals (16). Several attempts have been made to target CAFs and the stroma; however, they have not been successful despite promising preclinical studies $(9,17)$. For example, genetic depletion of alpha-smooth muscle actin ( $\alpha$ SMA) myofibroblasts in the stroma resulted in undifferentiated and invasive tumors with diminished survival (18). In metastatic PDAC patients, treatment with a pegylated recombinant human hyaluronidase (PEGPH20) combined with modified fluorouracil, leucovorin, irinotecan, and oxaliplatin (mFOLFIRINOX) did not improve progression-free or overall survival (19). Trials using hedgehog $(\mathrm{Hh})$ pathway inhibitors in combination with gemcitabine showed that the addition of Hh inhibitors was not superior to gemcitabine alone, and one study was prematurely terminated as patients treated with the Hh inhibitor did worse than the control arm (20-22). Despite these failures, targeting and modifying CAFs and the ECM continues to remain a topic of interest due to the substantial roles they play in tumor development, growth, and metastasis (23).

The cross-regulated and interacting networks of ECM proteins are fundamental to tumor homeostasis and tumorigenic activity like growth and metastasis (24-27) and must be further understood. This dynamic environment provides a reservoir for signaling molecules and prompts tumor cell activity via mechanical forces and biochemical signaling. This review covers the composition and general roles and regulation of the ECM in PDAC, key proteins in the ECM, and potential and ongoing targeting strategies.

\section{ECM OVERVIEW}

The ECM is a non-cellular component present in all tissue and provides the essential physical scaffolding, as well as biochemical and biomechanical cues to the surrounding cellular components. Consisting of water, proteins, and polysaccharides, the ECM composition adjusts based on the needs of the surrounding microenvironment. Most tissue require an ECM as an interstitial matrix in which the ECM is a 3-dimensional lattice supporting the surrounding cells of the stroma or a basement membrane in which the ECM is a matrix between epithelial and stromal layers of cells. Change in ECM architecture is a result of malignant cell transformation in many cancers, thus demonstrating the influence of biomechanical cues from the $\operatorname{ECM}(28,29)$.

Tumor stroma has often been portrayed as a contributor to the development of the disease and tumor progression. However, several recent preclinical and clinical studies have shown that stroma-depletion can lead to a more aggressive disease $(11,18$, $20,30,31)$. In patients, we and others have found that increased stroma correlates with improved survival and that stroma content at solid organ metastases is decreased $(13,14)$. Reduction of ECM through lysyl oxidase (LOX) inhibition in mouse models led to accelerated tumor growth (13).

Thus, the stroma and ECM play a dichotomous role in the TME as a tumor-promoting and tumor-inhibiting component, and selectively targeting the stroma and ECM may be the key. However, a more complete understanding of the stroma and the TME is necessary for this to succeed. The PDAC ECM is primarily composed of collagens, integrins, proteoglycans, glycoproteins, and proteases which all interact with tumor cells through a variety of mechanisms $(32,33)$ (Figure 1). Among these, collagens are the most abundant component.

\section{COLLAGENS}

The PDAC ECM contains combinations of type I, III, IV, V, and XV collagens $(32,34,35)$. The interaction between collagen and the basement membrane proteins within the ECM plays an important role during malignant transformation $(36,37)$. Increased desmoplasia is thought to contribute to disruption of the basement membrane leading to increased exposure of PDAC cells to interstitial collagens and reduction of basement membrane collagens (33). In PDAC, lower collagen I and IV is associated with undifferentiated PDAC tumors (38). Basement membrane proteins are suggested to be tumor-inhibiting by restricting the epithelial-to-mesenchymal transition (EMT), whereas interstitial collagens may promote tumor growth through other mechanisms. Preclinical studies have shown that collagen may contribute to therapy resistance by modulating signaling pathways (39-41). In patients, studies have found that imaging characteristics may be reflective of stroma content and patient outcome $(14,42)$.

\section{Collagens I, III, IV, and V}

Collagen $\mathrm{I}$ is among the most abundant collagen in PDAC stroma and is generally suggested to be responsible for most of the desmoplastic reaction and has been associated with reduced survival in PDAC patients (43-45). However, when C-terminal prodomains of collagen I are cleaved by procollagen Cproteinase activity, collagen I may restrain tumor growth (46, 47). In addition, the presence of collagen I in the TME does not appear to inhibit T-cell infiltration (48), further suggesting the stroma has roles beyond a physical barrier. Collagen III is the second most abundant collagen present in the PDAC ECM (32). 


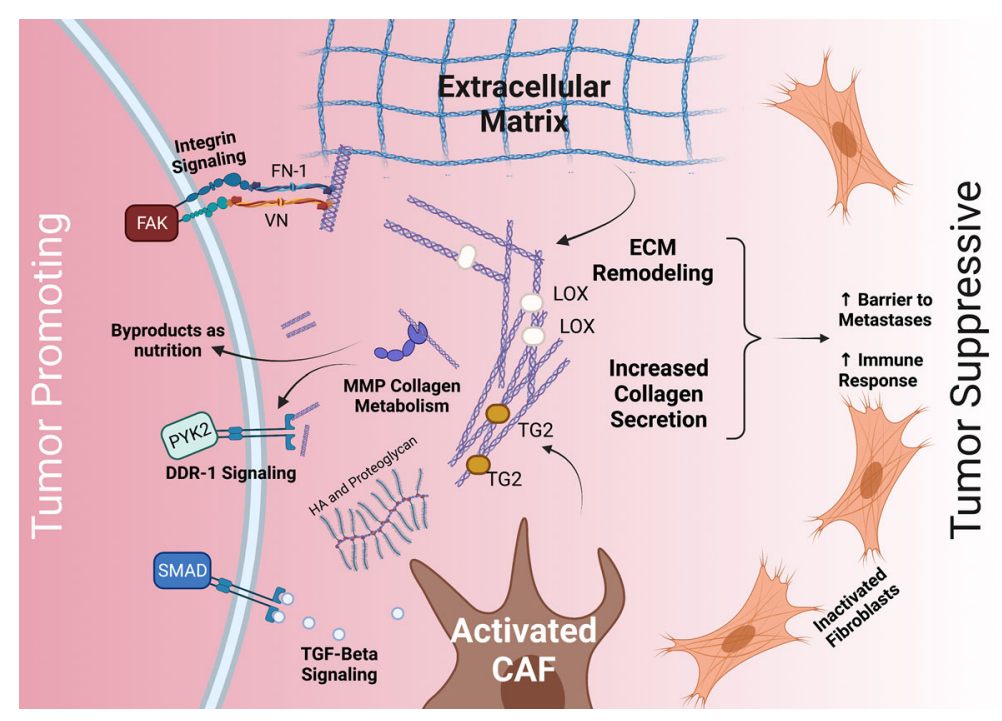

FIGURE 1 | The dichotomous role of the stroma and common interactions between PDAC tumor cells, the ECM, and CAFs. The stroma's ECM plays both a tumor promoting role (left) and a tumor suppressive role (right). Tumor promoting roles may include integrin, TGF $3 / S M A D$, and DDR-1 signaling, as well as providing nutrition via collagen fragments. Tumor suppressive roles may include providing a barrier to metastases and increasing immune response. The ECM (middle) is deposited by CAFs and modulated by MMP, LOX, TG2, HA, and others. CAF, cancer associated fibroblasts; TGF- beta, transforming growth factor beta; HA, hyaluronan; FN-1, fibronectin 1; VN, vitronectin; DDR-1, discoidin receptor 1; PYK2, FAK-related protein tyrosine kinase; FAK, focal adhesion kinase; TG2, tissue transglutimase; LOX, lysyl oxidase.

Like collagen I, collagen III may suppress tumor growth when cleaved (32). In addition, the ratio of collagen III to collagen III peptide fragments may be predictive of improved patient survival (49). Collagen IV, a collagen commonly found in the interstitial space, is overexpressed and deposited in the stroma by PDAC cells (50). In vitro assays using $\alpha 1$ (IV)-siRNA demonstrated that collagen IV silencing reduces tumor cell proliferation and migration and increases apoptosis (51). Lastly, the fibrillar collagen, collagen $\mathrm{V}$, is often identified as PSC-derived in PDAC and can be blocked by inhibiting $\beta 1$-integrin signaling. Genetic knock-down of collagen V in orthotopic mouse models demonstrated reduced tumor metastasis and angiogenesis (52).

\section{Collagen Signaling}

ECM collagens interact with signaling integrins expressed on the surface of PDAC cells. Collagens bind with the $\alpha$ - and $\beta$-subunits of integrins depending on the integrin specificity of the collagen subtype (53). Interstitial collagens I, IV, and V have a high affinity for integrin $\alpha 2 \beta 1$, and the interaction between collagen I or $\mathrm{V}$ with $\alpha 2 \beta 1$ promotes proliferation and migration of PDAC cells $(51,52,54-56)$. Like integrin-mediated signaling, collagens also interact with the cell surface receptor discoidin receptor 1 (DDR-1), a tyrosine kinase overexpressed by PDAC cells. Active DDR-1 activates FAK-related protein tyrosine kinase (PYK2) (57).

\section{Collagen as Nutrients}

Proliferating tumor cells require a constant supply of nutrients which are scarcely present in the dense desmoplastic tissue. Furthermore, the TME is generally hypoxic due to increased intra-tumoral oncotic pressure that decreases tissue perfusion. To adapt, PDAC cells may use large macropinosomes to nonspecifically take up nutrients from the surrounding TME in bulk (58-60). In this way, PDAC cells are thought to actively scavenge the TME's breakdown products and use collagen-derived proline as a primary source of energy in the absence of glucose $(61,62)$ (Figure 1). Likewise, proline oxidase (PRODH1) is overexpressed in proline catabolizing PDAC cells (62).

\section{INTEGRINS, PROTEOGLYCANS, AND GLYCOPROTEINS}

In addition to collagen, the TME also contains integrins, proteoglycans, and glycoproteins. Integrins mediate the interactions between TME cell-types and ECM proteins like proteoglycans and glycoproteins. Both proteoglycans and glycoproteins undergo post-translational glycosylation which modulates their functions and conformation. Aberrant glycosylation, a hallmark of several cancers, modifies the behavior of proteoglycans and glycoproteins in the TME; therefore, it is expected that the two classes of proteins play several modified roles in the TME (63).

\section{Integrins}

Integrins are transmembrane cell-surface receptors that heterodimerize upon binding ECM glycoproteins like fibronectin (FN1) and vitronectin (VN), collagens, and laminin (64). These cell-surface receptors are the major cell-adhesion receptors that interact with the ECM. In addition to directly 
contacting the ECM, activated integrins recruit the adhesome to the cytosolic tail of the integrin, a complex assortment of signaling, scaffolding, and cytoskeletal proteins (65-67). Differentially expressed in several solid tumors including PDAC, integrin roles are multi-faceted and participate in the metastatic cascade (68-70). Integrin-to-ECM contact points serve as molecular clutches to propel tumor cells forward by converting actin-polymerization into traction force $(71,72)$. In addition, by promoting the expression of matrix metalloproteinases (MMPs), integrins increase the proteolytic activity within the ECM and may facilitate the release of individual cancer cells or cell clusters from the TME (73). Integrin expression on cancer cells and endothelial cells has also been implicated in extravasation (74). In particular, PDAC zebrafish and mouse models demonstrated that the interaction between $\alpha 5$ integrin and neuropilin-2 facilitates the binding of cancer cells to the endothelium (75). Knockdown using lentiviral RNA-interference reduced cell adhesion, migration, and proliferation in vitro and vivo (76). In PDAC mouse models, the galectin-3 (GAL3) interaction with $\alpha v \beta 3$ integrin may serve as an underlying mechanism of KRAS addiction and increase nutrient uptake via micropinocytosis (77). Altogether, PDAC has demonstrated overexpression of members of the integrin family like $\beta 1, \beta 3$, and $\beta 6$ compared to normal pancreas $(64,69)$.

\section{Glycoproteins and Proteoglycans}

The glycoprotein galectin-1 (GAL1) has been found to be upregulated in the PDAC TME, alongside other glycoproteins like periostin and fibulin and is lowly expressed in long-term ( $\geq 10$ years) survivors of PDAC (78-80). Loss of GAL1 in murine models leads to reduced stromal activation and increased cytotoxic T-cell infiltration (81). FN1 and VN are thought to serve as scaffolding proteins in the PDAC TME and regulate cellular processes $(82,83)$. FN1 enables tumor cells to infiltrate the basement membrane, stimulates their proliferation, and bridges the interactions between ECM collagens and integrins (84-86) (Figure 1). FN1 is also known to stimulate transforming growth factor- $\beta$ (TGF $\beta$ ) secretion, in turn promoting the activation of the stroma (87). Secreted protein acidic and rich in cysteine (SPARC) is another major glycoprotein in the PDAC stroma that modulates ECM organization by directly binding to collagens I, III, IV, and V $(88,89)$. In addition, SPARC, expressed in the stroma from fibroblasts, regulates the interactions between integrins and ECM proteins by binding $\alpha 5 \beta 1$ focal adhesion sites (90). SPARC deficient mice demonstrated reduced collagen fibrillogenesis, and elevated metastasis (88).

The glycoprotein subclass, proteoglycans, often modulate the hydration level of the interstitial fluid, and in turn interstitial pressure, through its interactions with hyaluronic acid (HA) (91). However, HA modulation of interstitial pressure is suggested to be dependent on the collagen-richness of the TME and may not occur in collagen-replete TMEs (92). The TME of PDAC overproduces an abundance of HA beginning at the pre-malignant intraepithelial neoplasia (PanIN) stage (17). When HA is enzymatically depleted in mouse models, the delivery of cytotoxic therapies is enhanced, likely due to a compromised ECM lacking HA $(17,93)$.

\section{Secretome Studies}

PDAC secretome analyses aim to examine the surrounding PDAC environment to identify aberrant proteins or molecules that may be influence tumor progression. A meta-analysis of 20 PDAC secretome studies from cell lines and patient tissues found that proteins associated with extracellular exosomes, blood microparticles, membrane-bound, secretory lumen and cytoplasmic membrane-bound vesicles, were most commonly found (94). Notable proteins found among the secretome and proteome across 20 secretome studies and 35 proteome studies include TGF $\beta$ induced (TGFBI), vimentin, and fibronectin (94). Using 3D organotypic cell cultures, Biondani et al. demonstrated that incubating cells with increasing type I collagen promoted the secretion of pro-angiogenic and growth factors like epidermal growth factor (EGF), matrix metalloproteinase 9 (MMP9), and vascular endothelial growth factor (VEGF) (95).

\section{REGULATION OF THE ECM}

PSCs are thought to maintain the balance between ECM synthesis and degradation and serve as a cellular reservoir for vitamin A and lipids (96). In the presence of tumor cells, PSCs assume an "activated" state in which they excessively deposit ECM proteins; become elongated in shape; and demonstrate increased expression of $\alpha \mathrm{SMA}$, collagens, immune-modulating, and other tumor-promoting genes (96). The formation of CAFs from PSCs is thought to be mediated by the PDAC secretome, which is abundant in fibroblast growth factor 2 (FGF2), TGF $\beta$, and the paracrine and autocrine signaling regulator, sonic hedgehog (Shh) $(97,98)$. Shh functions to attract and activate PSCs, as PSCs demonstrate enhanced migration towards Shh overexpressing PDAC cells $(98,99)$. PSC activation through paracrine signaling has been shown to be inhibited with metformin, an activator of AMP-activated protein kinase (AMPK) (100).

TGF $\beta$ may suppress tumor growth in the early stages of carcinogenesis by inhibiting the proliferation of epithelial cells (101). However, in late stages of carcinogenesis, TGF $\beta$ promotes ECM deposition and tumor progression (101). A potent activator of PSCs, TGF $\beta$ mediates the interaction between the TME and tumor cells by binding TGF $\beta$ cell surface receptors. In PDAC, TGF $\beta$ promotes the deposition of several ECM proteins including fibronectin and collagens (102). On the surface of tumor cells, TGF $\beta$ receptor bind TGF $\beta$ to regulate downstream Smad-mediated gene transcription (103). PDAC-secreted TGF $\beta 1$ and FGF2 then promote ECM deposition by PSCs, as well as a positive feedback loop whereby PSCs secrete additional TGF $\beta 1$ that bind to TGF $\beta 1$-receptors found on the surface of PSCs. Once activated, PSCs, also known as CAFs, further modulate the ECM through a variety of mechanisms.

Tissue stiffness has been shown to enhance tumor cell proliferation in models of breast cancer (104). Stiff ECM matrices modulate vimentin, E-cadherin (CDH1), and ECM 
MMP activity $(105,106)$. Stiffening of the stroma is enhanced by collagen cross-linking carried out by LOX and tissue transglutaminase 2 (TG2) (107, 108) (Figure 1). LOX expression is increased under hypoxic conditions and systematic neutralization of LOX results in reduced proliferation and improved survival in mouse models (13, 107). On the other hand, TG2 secreted into the ECM promotes collagen I cross-linking and stimulates CAFs to produce additional collagen I $(108,109)$. In pancreatic tissue, TG2 is mildly expressed unless malignancy is present (108). Similar to stiffness, increased collagen fiber thickness is associated with poor patient outcome (110). The additional cross-linked collagen and stiff ECM, prompted by TG2 and/or LOX, activates yesassociated protein (YAP) and the transcriptional coactivator with a PDZ-binding motif (TAZ) that enhances cell proliferation (105). It is suggested that the YAP/TAZ signaling is the central hub for the cellular response to external mechanical cues, highlighted by increased nuclear localization of YAP/TAZ in response to mechanical stiffness (111-113).

\section{TARGETING THE ECM}

\section{Hyaluronic Acid}

The rationale for targeting the ECM as an adjunct to chemotherapy in PDAC relies on our understanding of the roles that ECM plays in promoting tumorigenesis. Early studies in mouse models showed that tumors with a high HA content had increased interstitial pressure that resulted in vascular collapse and diminished tumor perfusion. Treating these mice with a hyaluronidase inhibitor reversed these effects, creating an amenable environment for intra-tumoral drug delivery $(17,114)$. Since HA contributed to intra-tumoral pressure which in-turn affected drug delivery, the hypothesis was that targeting HA would improve drug delivery and efficacy. In SWOG S1313 (NCT01959139), PEGPH20 was evaluated in combination with mFOLFIRINOX and in the HALO trial (NCT02715804), in combination with nab-paclitaxel plus gemcitabine (Table 1) $(19,115)$. Unfortunately, some patients experienced strong adverse reactions to PEGPH20 and those who tolerated it did not have an improvement in overall survival (115).

TABLE 1 | Selected clinical trials evaluating stroma and ECM targeting.

\begin{tabular}{|c|c|c|c|c|c|}
\hline $\begin{array}{l}\text { NCT registry } \\
\text { number }\end{array}$ & Agent & Targets & Study population & Phase & Recruitment status \\
\hline NCT01959139 & PEGPH2O + modified FOLFIRINOX & HA + chemotherapy & Metastatic PDAC & $|/| \mid$ & Active, not recruiting \\
\hline NCT02715804 & PEGPH2O + nab-Paclitaxel + Gemcitabine & HA + chemotherapy & $\begin{array}{l}\text { Hyaluronan-high Stage IV } \\
\text { untreated PDAC }\end{array}$ & III & $\begin{array}{l}\text { Terminated (sponsor } \\
\text { decision) }\end{array}$ \\
\hline NCT01195415 & Vismodegib + Gemcitabine & Shh pathway + chemotherapy & Advance PDAC & $\|$ & Completed \\
\hline NCT01088815 & Vismodegib + Gemcitabine + nab-Paclitaxel & Shh pathway + chemotherapy & Metastatic PDAC & $\|$ & Completed \\
\hline NCT01064622 & Vismodegib + Gemcitabine & Shh pathway + chemotherapy & $\begin{array}{l}\text { Recurrent or metastatic } \\
\text { PDAC }\end{array}$ & $|/| \mid$ & Completed \\
\hline NCT01383538 & IPI-926 + FOLFIRINOX & Shh pathway + chemotherapy & Advance PDAC & I & Completed \\
\hline NCT01585701 & AT13148 & $\begin{array}{l}\text { Muti-AGC kinases including } \\
\text { ROCK-AKT }\end{array}$ & Advance solid tumors & I & Completed \\
\hline NCT03519308 & $\begin{array}{l}\text { Paricalcitol + Nivolumab + nab-Paclitaxel + } \\
\text { Gemcitabine }\end{array}$ & $\begin{array}{l}\text { Vitamin D Receptor + PD-L1 + } \\
\text { chemotherapy }\end{array}$ & Resectable PDAC & I & Recruiting \\
\hline NCT04617067 & Paricalcitol + Gemcitabine + nab-Paclitaxel & $\begin{array}{l}\text { Vitamin D Receptor + } \\
\text { chemotherapy }\end{array}$ & Advance PDAC & $\|$ & Recruiting \\
\hline NCT04524702 & $\begin{array}{l}\text { Paricalcitol + Hydroxychloroquine + } \\
\text { Gemcitabine + nab-Paclitaxel }\end{array}$ & $\begin{array}{l}\text { Vitamin D Receptor + autophagy + } \\
\text { chemotherapy }\end{array}$ & Advance or metastatic PDAC & $\|$ & Recruiting \\
\hline NCT03331562 & Paricalcitol + Pembrolizumab & Vitamin D Receptor + PD-1 & PDAC (maintenance) & $\|$ & Completed \\
\hline NCT02930902 & $\begin{array}{l}\text { Paricalcitol + Pembrolizumab + Gemcitabine + } \\
\text { nab-Paclitaxel }\end{array}$ & $\begin{array}{l}\text { Vitamin D Receptor + PD-1 + } \\
\text { chemotherapy }\end{array}$ & Resectable PDAC & 1 & Active, not recruiting \\
\hline NCT02030860 & Paricalcitol + nab-Paclitaxel + Gemcitabine & $\begin{array}{l}\text { Vitamin D Receptor }+ \\
\text { chemotherapy }\end{array}$ & Resectable PDAC & NA & Completed \\
\hline NCT03138720 & $\begin{array}{l}\text { Paricalcitol + nab-Paclitaxel + Gemcitabine + } \\
\text { Cisplatin }\end{array}$ & $\begin{array}{l}\text { Vitamin D Receptor + } \\
\text { chemotherapy }\end{array}$ & Advance PDAC & $\|$ & Active, not recruiting \\
\hline NCT03415854 & $\begin{array}{l}\text { Paricalcitol + nab-Paclitaxel + Gemcitabine + } \\
\text { Cisplatin }\end{array}$ & Vitamin D Receptor & Metastatic PDAC & $\|$ & Active, not recruiting \\
\hline NCT02754726 & $\begin{array}{l}\text { Paricalcitol + Nivolumab + nab-Paclitaxel + } \\
\text { Gemcitabine + Cisplatin }\end{array}$ & $\begin{array}{l}\text { Vitamin D Receptor + PD-L1 + } \\
\text { chemotherapy }\end{array}$ & & & Active, not recruiting \\
\hline NCT01646203 & LY3022859 & Tßrii & Advance solid tumors & 1 & Completed \\
\hline NCT00557856 & PF-03446962 & Tßri & Advance solid tumors & 1 & Completed \\
\hline NCT04296942 & Bintrafusp alfa & Tßrii + PD-L1 & Advance solid tumors & 1 & Completed \\
\hline NCT01682187 & Galunisertib & Tßri & Advance solid tumors & I & Completed \\
\hline NCT01373164 & Galunisertib + Gemcitabine & Tßri + chemotherapy & $\begin{array}{l}\text { Inoperable or metastatic } \\
\text { PDAC }\end{array}$ & $|/| \mid$ & Completed \\
\hline NCT02154646 & Galunisertib + Gemcitabine & Tßri + chemotherapy & $\begin{array}{l}\text { Inoperable or metastatic } \\
\text { PDAC }\end{array}$ & I & Completed \\
\hline NCT02734166 & Galunisertib + Durvalumab & $\mathrm{T} \beta \mathrm{ri}+\mathrm{PD}-\mathrm{L} 1$ & Metastatic PDAC & 1 & Completed \\
\hline NCT03192345 & SAR438459 + Cemiplimab & $\operatorname{Tgf} \beta 1, \operatorname{tg} f \beta 2$, and $\operatorname{tg} f \beta+P D-L 1$ & Advance solid tumors & 1 & Active, recruiting \\
\hline
\end{tabular}




\section{Hedgehog Pathway}

Treating mice with Shh inhibitors in addition to chemotherapy improved tumor microvascular density and survival (9). The addition of Shh inhibitors to either FOLFIRINOX or gemcitabine in clinical trials failed to improve overall survival and, in some cases, was associated with a worse outcome (Table 1) $(20,30)$. These studies were done prior to our understanding of CAF heterogeneity, and recent work has been done to further elucidate the underlying biology responsible for the discrepancy in clinical findings. Recent studies suggest that blocking the Shh signaling pathway may shift the stroma CAF populations from myofibroblast-CAFs (myCAFs) to inflammatory CAFs (iCAFs) and promote an immunosuppressive TME (116).

\section{Rho Kinase Inhibitors}

Rho kinase (ROCK) inhibitors alter PDAC cell cytoskeletal contractility and CAF contractility and may enable more favorable drug delivery in PDAC as well as inhibit PDAC metastasis. ROCK inhibition resulted in a disorganized ECM that blunted PDAC migration and invasion in vitro. In vivo models including both subcutaneous and intrasplenic injection found that administering ROCK-inhibitors prior to chemotherapy resulted in increased primary tumor response to chemotherapy and helped prevent the growth and establishment of liver metastases (117-120). A phase 1 study using a kinase inhibitor, AT13148, with anti-ROCKI/II activity was carried out in patients with metastatic solid tumors, but did not proceed further due to toxicity (Table 1) (121).

\section{Vitamin D}

Vitamin D halts the secretion of collagen in several cell types, possibly by disrupting TGF- $\beta$ signaling $(103,122)$. The vitamin $D$ receptor (VDR) has been shown to regulate transcription of PSCs and CAFs $(123,124)$. Treatment with VDR ligand, calcipotriol, reprograms the stroma, decreases inflammation and improves response to gemcitabine (123). Other studies have shown that while calcipotriol decreases CAF migration and inflammation, it also may negatively affect $\mathrm{T}$ cell effector functions $(125,126)$. Several studies of paricalcitol, a vitamin D analogue, in combination with chemotherapies and immunotherapies are ongoing (Table 1).

\section{TGF $\beta$}

Preclinical experimental data has suggested that blocking TGF $\beta$ mediated signaling likely enhances antitumor effects in solid tumors. Further, PDAC is often characterized by high TGF $\beta$ expression levels (101). Several clinical trials have attempted to target TGF $\beta$ in a variety of cancers, but no TGF $\beta$-targeting

\section{REFERENCES}

1. Rahib L, Smith BD, Aizenberg R, Rosenzweig AB, Fleshman JM, Matrisian LM. Projecting Cancer Incidence and Deaths to 2030: The Unexpected Burden of Thyroid, Liver, and Pancreas Cancers in the United States. Cancer Res (2014) 74:2913. doi: 10.1158/0008-5472.CAN-14-0155

2. Siegel RL, Miller KD, Fuchs HE, Jemal A. Cancer Statistics, 2021. CA: A Cancer J Clin (2021) 71:7-33. doi: 10.3322/caac.21654 inhibitor has been approved for use (127). There is currently at least one ongoing clinical trial targeting TGF $\beta$ in PDAC (Table 1) that is investigating the pharmacokinetics, pharmacodynamics, and anti-tumor activity of SAR439459 alone and in combination with cemiplimab. SAR439459 is a pan-TGF $\beta$ neutralizing antibody that targets the three TGF $\beta$ isoforms (TGF $\beta 1,2$ and 3) and their interaction with type II TGF $\beta$ cell surface receptors (128).

\section{CONCLUDING REMARKS}

The ECM plays an important role in PDAC tumor growth, metastasis, and therapy resistance. Accumulating preclinical studies with patient-derived specimens indicate that targeting the dense desmoplastic ECM proteins of PDAC may provide promising clinically useful therapies. In clinical practice, we have yet to successfully target the ECM in a way that improves overall survival. The clinical shortcomings of once promising therapies are a humble reminder of the underlying complexity of tumor biology. Learning from these failures and developing a deeper understanding of the fundamental biology allows researchers to identify further vulnerabilities that should be considered when developing treatments. Tumor and CAF subtypes have been identified that were previously not known and will likely improve the outcome of ECM modulating studies if performed using reproducible subtyping methods and tailored targeting techniques $(15,16,129-133)$. Recent advances foster hope that ECM-modulating therapies are likely to become a crucial part of the toolkit for oncologists in the next few decades.

\section{AUTHOR CONTRIBUTIONS}

All authors listed have made a substantial direct and intellectual contribution to the work and approved it for publication.

\section{FUNDING}

This work was financially supported by the National Cancer Institute of the National Institutes of Health under the award numbers R01-CA199064 (JY) and T32-CA244125 (JK, VP).

\section{ACKNOWLEDGMENTS}

Figures for this publication were created with BioRender.com.

3. Balaban EP, Mangu PB, Khorana AA, Shah MA, Mukherjee S, Crane $\mathrm{CH}$, et al. Locally Advanced, Unresectable Pancreatic Cancer: American Society of Clinical Oncology Clinical Practice Guideline. J Clin Oncol (2016) 34:2654-68. doi: 10.1200/JCO.2016.67.5561

4. Conroy T, Desseigne F, Ychou M, Bouché O, Guimbaud R, Bécouarn Y, et al. FOLFIRINOX Versus Gemcitabine for Metastatic Pancreatic Cancer. New Engl J Med (2011) 364:1817-25. doi: 10.1056/ NEJMoa1011923 
5. Von Hoff DD, Ervin T, Arena FP, Chiorean EG, Infante J, Moore M, et al. Increased Survival in Pancreatic Cancer With Nab-Paclitaxel Plus Gemcitabine. New Engl J Med (2013) 369:1691-703. doi: 10.1056/ NEJMoa1304369

6. Golan T, Hammel P, Reni M, Van Cutsem E, Macarulla T, Hall MJ, et al. Maintenance Olaparib for Germline BRCA-Mutated Metastatic Pancreatic Cancer. New Engl J Med (2019) 381:317-27. doi: 10.1056/NEJMoa1903387

7. Pandol S, Edderkaoui M, Gukovsky I, Lugea A, Gukovskaya A. Desmoplasia of Pancreatic Ductal Adenocarcinoma. Clin Gastroenterol Hepatol (2009) 7: S44-7. doi: 10.1016/j.cgh.2009.07.039

8. Jacobetz MA, Chan DS, Neesse A, Bapiro TE, Cook N, Frese KK, et al. Hyaluronan Impairs Vascular Function and Drug Delivery in a Mouse Model of Pancreatic Cancer. Gut (2013) 62:112-20. doi: 10.1136/gutjnl2012-302529

9. Olive KP, Jacobetz MA, Davidson CJ, Gopinathan A, Mcintyre D, Honess D, et al. Inhibition of Hedgehog Signaling Enhances Delivery of Chemotherapy in a Mouse Model of Pancreatic Cancer. Science (2009) 324:1457-61. doi: $10.1126 /$ science. 1171362

10. Elahi-Gedwillo KY, Carlson M, Zettervall J, Provenzano PP. Antifibrotic Therapy Disrupts Stromal Barriers and Modulates the Immune Landscape in Pancreatic Ductal Adenocarcinoma. Cancer Res (2019) 79:372-86. doi: 10.1158/0008-5472.CAN-18-1334

11. Lee JJ, Perera RM, Wang H, Wu D-C, Liu XS, Han S, et al. Stromal Response to Hedgehog Signaling Restrains Pancreatic Cancer Progression. Proc Natl Acad Sci USA (2014) 111:E3091-100. doi: 10.1073/pnas.1411679111

12. Whittle MC, Izeradjene K, Rani PG, Feng L, Carlson MA, Delgiorno KE, et al. RUNX3 Controls a Metastatic Switch in Pancreatic Ductal Adenocarcinoma. Cell (2015) 161:1345-60. doi: 10.1016/ j.cell.2015.04.048

13. Jiang H, Torphy RJ, Steiger K, Hongo H, Ritchie AJ, Kriegsmann M, et al. Pancreatic Ductal Adenocarcinoma Progression Is Restrained by Stromal Matrix. J Clin Invest (2020) 130:4704-9. doi: 10.1172/JCI136760

14. Torphy RJ, Wang Z, True-Yasaki A, Volmar KE, Rashid N, Yeh B, et al. Stromal Content Is Correlated With Tissue Site, Contrast Retention, and Survival in Pancreatic Adenocarcinoma. JCO Precis Oncol (2018) 2018:1-12. doi: 10.1200/PO.17.00121

15. Sahai E, Astsaturov I, Cukierman E, Denardo DG, Egeblad M, Evans RM, et al. A Framework for Advancing Our Understanding of Cancer-Associated Fibroblasts. Nat Rev Cancer (2020) 20:174-86. doi: 10.1038/s41568-0190238-1

16. Öhlund D, Handly-Santana A, Biffi G, Elyada E, Almeida AS, Ponz-Sarvise $M$, et al. Distinct Populations of Inflammatory Fibroblasts and Myofibroblasts in Pancreatic Cancer. J Exp Med (2017) 214:579-96. doi: 10.1084/jem.20162024

17. Provenzano PP, Cuevas C, Chang AE, Goel VK, Von Hoff DD, Hingorani SR. Enzymatic Targeting of the Stroma Ablates Physical Barriers to Treatment of Pancreatic Ductal Adenocarcinoma. Cancer Cell (2012) 21:418-29. doi: 10.1016/j.ccr.2012.01.007

18. Özdemir BC, Pentcheva-Hoang T, Carstens JL, Zheng X, Wu C-C, Simpson TR, et al. Depletion of Carcinoma-Associated Fibroblasts and Fibrosis Induces Immunosuppression and Accelerates Pancreas Cancer With Reduced Survival. Cancer Cell (2014) 25:719-34. doi: 10.1016/ j.ccr.2014.04.005

19. Ramanathan RK, Mcdonough SL, Philip PA, Hingorani SR, Lacy J, Kortmansky JS, et al. Phase IB/II Randomized Study of FOLFIRINOX Plus Pegylated Recombinant Human Hyaluronidase Versus FOLFIRINOX Alone in Patients With Metastatic Pancreatic Adenocarcinoma: SWOG S1313. J Clin Oncol (2019) 37:1062-9. doi: 10.1200/JCO.18.01295

20. Kim EJ, Sahai V, Abel EV, Griffith KA, Greenson JK, Takebe N, et al. Pilot Clinical Trial of Hedgehog Pathway Inhibitor GDC-0449 (Vismodegib) in Combination With Gemcitabine in Patients With Metastatic Pancreatic Adenocarcinoma. Clin Cancer Res (2014) 20:5937-45. doi: 10.1158/10780432.CCR-14-1269

21. De Jesus-Acosta A, Sugar EA, O'dwyer PJ, Ramanathan RK, Von Hoff DD, Rasheed Z, et al. Phase 2 Study of Vismodegib, a Hedgehog Inhibitor, Combined With Gemcitabine and Nab-Paclitaxel in Patients With Untreated Metastatic Pancreatic Adenocarcinoma. Br J Cancer (2020) 122:498-505. doi: 10.1038/s41416-019-0683-3
22. Catenacci DVT, Junttila MR, Karrison T, Bahary N, Horiba MN, Nattam SR, et al. Randomized Phase Ib/II Study of Gemcitabine Plus Placebo or Vismodegib, a Hedgehog Pathway Inhibitor, in Patients With Metastatic Pancreatic Cancer. J Clin Oncol (2015) 33:4284-92. doi: 10.1200/ JCO.2015.62.8719

23. Neesse A, Bauer CA, Öhlund D, Lauth M, Buchholz M, Michl P, et al. Stromal Biology and Therapy in Pancreatic Cancer: Ready for Clinical Translation? Gut (2019) 68:159. doi: 10.1136/gutjnl-2018-316451

24. Humphrey JD, Dufresne ER, Schwartz MA. Mechanotransduction and Extracellular Matrix Homeostasis. Nat Rev Mol (2014) 15:802-12. doi: $10.1038 / \mathrm{nrm} 3896$

25. Pickup MW, Mouw JK, Weaver VM. The Extracellular Matrix Modulates the Hallmarks of Cancer. EMBO Rep (2014) 15:1243-53. doi: 10.15252/ embr.201439246

26. Ligorio M, Sil S, Malagon-Lopez J, Nieman LT, Misale S, Di Pilato M, et al. Stromal Microenvironment Shapes the Intratumoral Architecture of Pancreatic Cancer. Cell (2019) 178:160-175.e127. doi: 10.1016/ j.cell.2019.05.012

27. Xu Q, Wang Z, Chen X, Duan W, Lei J, Zong L, et al. Stromal-Derived Factor-1 $\alpha /$ CXCL12-CXCR4 Chemotactic Pathway Promotes Perineural Invasion in Pancreatic Cancer. Oncotarget (2015) 6:4717-32. doi: 10.18632/oncotarget.3069

28. Wu XZ, Chen D, Xie GR. Extracellular Matrix Remodeling in Hepatocellular Carcinoma: Effects of Soil on Seed? Med Hypotheses (2006) 66:1115-20. doi: 10.1016/j.mehy.2005.12.043

29. Parker AL, Cox TR. The Role of the ECM in Lung Cancer Dormancy and Outgrowth. Front Oncol (2020) 10:1766-6. doi: 10.3389/fonc.2020.01766

30. Ko AH, Loconte N, Tempero MA, Walker EJ, Kate Kelley R, Lewis S, et al. A Phase I Study of FOLFIRINOX Plus IPI-926, A Hedgehog Pathway Inhibitor, for Advanced Pancreatic Adenocarcinoma. Pancreas (2016) 45:370-5. doi: 10.1097/MPA.0000000000000458

31. Rhim AD, Oberstein PE, Thomas DH, Mirek ET, Palermo CF, Sastra SA, et al. Stromal Elements Act to Restrain, Rather Than Support, Pancreatic Ductal Adenocarcinoma. Cancer Cell (2014) 25:735-47. doi: 10.1016/ j.ccr.2014.04.021

32. Tian C, Clauser KR, Öhlund D, Rickelt S, Huang Y, Gupta M, et al. Proteomic Analyses of ECM During Pancreatic Ductal Adenocarcinoma Progression Reveal Different Contributions by Tumor and Stromal Cells. Proc Natl Acad Sci USA (2019) 116:19609-18. doi: 10.1073/pnas. 1908626116

33. Weniger M, Honselmann KC, Liss AS. The Extracellular Matrix and Pancreatic Cancer: A Complex Relationship. Cancers (2018) 10:316. doi: $10.3390 /$ cancers 10090316

34. Van Agtmael T, Bruckner-Tuderman L. Basement Membranes and Human Disease. Cell Tissue Res (2009) 339:167. doi: 10.1007/s00441-009-0866-y

35. Karsdal MA, Nielsen SH, Leeming DJ, Langholm LL, Nielsen MJ, ManonJensen T, et al. The Good and the Bad Collagens of Fibrosis - Their Role in Signaling and Organ Function. Advanced Drug Delivery Rev (2017) 121:4356. doi: 10.1016/j.addr.2017.07.014

36. Xu S, Xu H, Wang W, Li S, Li H, Li T, et al. The Role of Collagen in Cancer: From Bench to Bedside. J Transl Med (2019) 17:309. doi: 10.1186/s12967019-2058-1

37. Chen D, Liu Z, Liu W, Fu M, Jiang W, Xu S, et al. Predicting Postoperative Peritoneal Metastasis in Gastric Cancer With Serosal Invasion Using a Collagen Nomogram. Nat Commun (2021) 12:179-9. doi: 10.1038/s41467020-20429-0

38. Wegner CS, Gaustad J-V, Andersen LMK, Simonsen TG, Rofstad EK. Diffusion-Weighted and Dynamic Contrast-Enhanced MRI of Pancreatic Adenocarcinoma Xenografts: Associations With Tumor Differentiation and Collagen Content. J Transl Med (2016) 14:161-1. doi: 10.1186/s12967-016$0920-y$

39. Senthebane DA, Jonker T, Rowe A, Thomford NE, Munro D, Dandara C, et al. The Role of Tumor Microenvironment in Chemoresistance: 3d Extracellular Matrices as Accomplices. Int J Mol Sci (2018) 19:2861. doi: 10.3390/ijms 19102861

40. Sterzyńska K, Klejewski A, Wojtowicz K, Świerczewska M, Nowacka M, Kaźmierczak D, et al. Mutual Expression of ALDH1A1, LOX, and Collagens in Ovarian Cancer Cell Lines as Combined CSCs- and ECM-Related Models 
of Drug Resistance Development. Int J Mol Sci (2018) 20:54. doi: 10.3390/ ijms 20010054

41. Jakubzig B, Baltes F, Henze S, Schlesinger M, Bendas G. Mechanisms of Matrix-Induced Chemoresistance of Breast Cancer Cells-Deciphering Novel Potential Targets for a Cell Sensitization. Cancers (2018) 10:495. doi: $10.3390 /$ cancers 10120495

42. Koay EJ, Lee Y, Cristini V, Lowengrub JS, Kang YA, Lucas FAS, et al. A Visually Apparent and Quantifiable CT Imaging Feature Identifies Biophysical Subtypes of Pancreatic Ductal Adenocarcinoma. Clin Cancer Res (2018) 24:5883-94. doi: 10.1158/1078-0432.CCR-17-3668

43. Imamura T, Iguchi $\mathrm{H}$, Manabe $\mathrm{T}$, Ohshio G, Yoshimura $\mathrm{T}$, Wang Z-H, et al. Quantitative Analysis of Collagen and Collagen Subtypes I, III, and V in Human Pancreatic Cancer, Tumor-Associated Chronic Pancreatitis, and Alcoholic Chronic Pancreatitis. Pancreas (1995) 11:357-64. doi: 10.1097/ 00006676-199511000-00007

44. Mollenhauer J, Roether I, Kern HF. Distribution of Extracellular Matrix Proteins in Pancreatic Ductal Adenocarcinoma and Its Influence on Tumor Cell Proliferation In Vitro. Pancreas (1987) 2:14-24. doi: 10.1097/00006676198701000-00003

45. Whatcott CJ, Diep CH, Jiang P, Watanabe A, Lobello J, Sima C, et al. Desmoplasia in Primary Tumors and Metastatic Lesions of Pancreatic Cancer. Clin Cancer Res (2015) 21:3561-8. doi: 10.1158/1078-0432.CCR14-1051

46. Tian C, Huang Y, Clauser KR, Rickelt S, Lau AN, Carr SA, et al. Suppression of Pancreatic Ductal Adenocarcinoma Growth and Metastasis by Fibrillar Collagens Produced Selectively by Tumor Cells. Nat Commun (2021) 12:2328-8. doi: 10.1038/s41467-021-22490-9

47. Madsen CD. Pancreatic Cancer Is Suppressed by Fibroblast-Derived Collagen I. Cancer Cell (2021) 39:451-3. doi: 10.1016/j.ccell.2021.02.017

48. Carstens JL, Correa De Sampaio P, Yang D, Barua S, Wang H, Rao A, et al. Spatial Computation of Intratumoral T Cells Correlates With Survival of Patients With Pancreatic Cancer. Nat Commun (2017) 8:15095-5. doi: 10.1038/ncomms 15095

49. Willumsen N, Ali SM, Leitzel K, Drabick JJ, Yee N, Polimera HV, et al. Collagen Fragments Quantified in Serum as Measures of Desmoplasia Associate With Survival Outcome in Patients With Advanced Pancreatic Cancer. Sci Rep (2019) 9:19761-1. doi: 10.1038/s41598-019-56268-3

50. Ohlund D, Lundin C, Ardnor B, Oman M, Naredi P, Sund M. Type IV Collagen Is a Tumour Stroma-Derived Biomarker for Pancreas Cancer. $\mathrm{Br} \mathrm{J}$ Cancer (2009) 101:91-7. doi: 10.1038/sj.bjc.6605107

51. Öhlund D, Franklin O, Lundberg E, Lundin C, Sund M. Type IV Collagen Stimulates Pancreatic Cancer Cell Proliferation, Migration, and Inhibits Apoptosis Through an Autocrine Loop. BMC Cancer (2013) 13:154. doi: 10.1186/1471-2407-13-154

52. Berchtold S, Grünwald B, Krüger A, Reithmeier A, Hähl T, Cheng T, et al. Collagen Type V Promotes the Malignant Phenotype of Pancreatic Ductal Adenocarcinoma. Cancer Lett (2015) 356:721-32. doi: 10.1016/ j.canlet.2014.10.020

53. Tulla M, Pentikäinen OT, Viitasalo T, Käpylä J, Impola U, Nykvist P, et al. Selective Binding of Collagen Subtypes by Integrin A1l, A2l, and A101 Domains *. J Biol Chem (2001) 276:48206-12. doi: 10.1074/jbc.M104058200

54. Grzesiak JJ, Bouvet M. Determination of the Ligand-Binding Specificities of the $\alpha 2 \beta 1$ and $\alpha 1 \beta 1$ Integrins in a Novel 3-Dimensional In Vitro Model of Pancreatic Cancer. Pancreas (2007) 34:220-8. doi: 10.1097/01.mpa.0000250129. 64650.6

55. Armstrong T, Packham G, Murphy LB, Bateman AC, Conti JA, Fine DR, et al. Type I Collagen Promotes the Malignant Phenotype of Pancreatic Ductal Adenocarcinoma. Clin Cancer Res (2004) 10:7427. doi: 10.1158/10780432.CCR-03-0825

56. Ruggiero F, Comte J, Cabañas C, Garrone R. Structural Requirements for Alpha 1 Beta 1 and Alpha 2 Beta 1 Integrin Mediated Cell Adhesion to Collagen V. J Cell Sci (1996) 109(Pt 7):1865-74. doi: 10.1242/ jcs.109.7.1865

57. Valiathan RR, Marco M, Leitinger B, Kleer CG, Fridman R. Discoidin Domain Receptor Tyrosine Kinases: New Players in Cancer Progression. Cancer metastasis Rev (2012) 31:295-321. doi: 10.1007/s10555-012-9346-Z

58. Commisso C, Davidson SM, Soydaner-Azeloglu RG, Parker SJ, Kamphorst JJ, Hackett S, et al. Macropinocytosis of Protein Is an Amino Acid Supply
Route in Ras-Transformed Cells. Nature (2013) 497:633-7. doi: 10.1038/ nature12138

59. Bar-Sagi D, Feramisco JR. Induction of Membrane Ruffling and Fluid-Phase Pinocytosis in Quiescent Fibroblasts by Ras Proteins. Science (1986) 233:1061. doi: 10.1126/science.3090687

60. Davidson SM, Jonas O, Keibler MA, Hou HW, Luengo A, Mayers JR, et al. Direct Evidence for Cancer-Cell-Autonomous Extracellular Protein Catabolism in Pancreatic Tumors. Nat Med (2017) 23:235-41. doi: $10.1038 / \mathrm{nm} .4256$

61. Kamphorst JJ, Nofal M, Commisso C, Hackett SR, Lu W, Grabocka E, et al. Human Pancreatic Cancer Tumors Are Nutrient Poor and Tumor Cells Actively Scavenge Extracellular Protein. Cancer Res (2015) 75:544-53. doi: 10.1158/0008-5472.CAN-14-2211

62. Olivares O, Mayers JR, Gouirand V, Torrence ME, Gicquel T, Borge L, et al. Collagen-Derived Proline Promotes Pancreatic Ductal Adenocarcinoma Cell Survival Under Nutrient Limited Conditions. Nat Commun (2017) 8:16031. doi: 10.1038/ncomms 16031

63. Pan S, Brentnall TA, Chen R. Glycoproteins and Glycoproteomics in Pancreatic Cancer. World J Gastroenterol (2016) 22:9288-99. doi: 10.3748/ wjg.v22.i42.9288

64. Hamidi H, Ivaska J. Every Step of the Way: Integrins in Cancer Progression and Metastasis. Nat Rev Cancer (2018) 18:533-48. doi: 10.1038/s41568-0180038-z

65. Horton ER, Byron A, Askari JA, Ng DHJ, Millon-Frémillon A, Robertson J, et al. Definition of a Consensus Integrin Adhesome and its Dynamics During Adhesion Complex Assembly and Disassembly. Nat Cell Biol (2015) 17:1577-87. doi: 10.1038/ncb3257

66. Horton ER, Humphries JD, James J, Jones MC, Askari JA, Humphries MJ. The Integrin Adhesome Network at a Glance. J Cell Sci (2016) 129:4159-63. doi: $10.1242 /$ jcs. 192054

67. Zaidel-Bar R, Itzkovitz S, Ma'ayan A, Iyengar R, Geiger B. Functional Atlas of the Integrin Adhesome. Nat Cell Biol (2007) 9:858-67. doi: 10.1038/ ncb0807-858

68. Ahmed N, Pansino F, Clyde R, Murthi P, Quinn MA, Rice GE, et al. Overexpression of $\alpha v \beta 6$ Integrin in Serous Epithelial Ovarian Cancer Regulates Extracellular Matrix Degradation via the Plasminogen Activation Cascade. Carcinogenesis (2002) 23:237-44. doi: 10.1093/carcin/ 23.2.237

69. Baum O, Hlushchuk R, Forster A, Greiner R, Clézardin P, Zhao Y, et al. Increased Invasive Potential and Up-Regulation of MMP-2 in MDA-MB231 Breast Cancer Cells Expressing the $\beta 3$ Integrin Subunit. Int $J$ Oncol (2007) 30:325-32. doi: 10.3892/ijo.30.2.325

70. Sipos B, Hahn D, Carceller A, Piulats J, Hedderich J, Kalthoff H, et al. Immunohistochemical Screening for $\beta 6$-Integrin Subunit Expression in Adenocarcinomas Using a Novel Monoclonal Antibody Reveals Strong Up-Regulation in Pancreatic Ductal Adenocarcinomas In Vivo and In Vitro. Histopathology (2004) 45:226-36. doi: 10.1111/j.13652559.2004.01919.x

71. Gardel ML, Sabass B, Ji L, Danuser G, Schwarz US, Waterman CM. Traction Stress in Focal Adhesions Correlates Biphasically With Actin Retrograde Flow Speed. J Cell Biol (2008) 183:999-1005. doi: 10.1083/jcb.200810060

72. Yue J, Zhang K, Chen J. Role of Integrins in Regulating Proteases to Mediate Extracellular Matrix Remodeling. Cancer Microenviron Off J Int Cancer Microenviron Soc (2012) 5:275-83. doi: 10.1007/s12307-012-0101-3

73. Munshi HG, Stack MS. Reciprocal Interactions Between Adhesion Receptor Signaling and MMP Regulation. Cancer Metastasis Rev (2006) 25:45-56. doi: 10.1007/s10555-006-7888-7

74. Hakanpaa L, Sipila T, Leppanen V-M, Gautam P, Nurmi H, Jacquemet G, et al. Endothelial Destabilization by Angiopoietin-2 via Integrin $\beta 1$ Activation. Nat Commun (2015) 6:5962-2. doi: 10.1038/ncomms6962

75. Cao Y, Hoeppner LH, Bach S, E G, Guo Y, Wang E, et al. Neuropilin-2 Promotes Extravasation and Metastasis by Interacting With Endothelial $\alpha 5$ Integrin. Cancer Res (2013) 73:4579-90. doi: 10.1158/0008-5472.CAN-130529

76. Grzesiak JJ, Tran Cao HS, Burton DW, Kaushal S, Vargas F, Clopton P, et al. Knockdown of the $\beta(1)$ Integrin Subunit Reduces Primary Tumor Growth and Inhibits Pancreatic Cancer Metastasis. Int J Cancer (2011) 129:2905-15. doi: $10.1002 /$ ijc. 25942 
77. Seguin L, Camargo MF, Wettersten HI, Kato S, Desgrosellier JS, Von Schalscha T, et al. Galectin-3, a Druggable Vulnerability for KRASAddicted Cancers. Cancer Discovery (2017) 7:1464-79. doi: 10.1158/21598290.CD-17-0539

78. Pan S, Chen R, Tamura Y, Crispin DA, Lai LA, May DH, et al. Quantitative Glycoproteomics Analysis Reveals Changes in N-Glycosylation Level Associated With Pancreatic Ductal Adenocarcinoma. J Proteome Res (2014) 13:1293-306. doi: 10.1021/pr4010184

79. Chen R, Pan S, Ottenhof NA, De Wilde RF, Wolfgang CL, Lane Z, et al. Stromal Galectin-1 Expression Is Associated With Long-Term Survival in Resectable Pancreatic Ductal Adenocarcinoma. Cancer Biol Ther (2012) 13:899-907. doi: 10.4161/cbt.20842

80. Chen R, Dawson DW, Pan S, Ottenhof NA, De Wilde RF, Wolfgang CL, et al. Proteins Associated With Pancreatic Cancer Survival in Patients With Resectable Pancreatic Ductal Adenocarcinoma. Lab investigation; J Tech Methods Pathol (2015) 95:43-55. doi: 10.1038/labinvest.2014.128

81. Orozco CA, Martinez-Bosch N, Guerrero PE, Vinaixa J, Dalotto-Moreno T, Iglesias M, et al. Targeting Galectin-1 Inhibits Pancreatic Cancer Progression by Modulating Tumor-Stroma Crosstalk. Proc Natl Acad Sci USA (2018) 115:E3769-78. doi: 10.1073/pnas.1722434115

82. To WS, Midwood KS. Plasma and Cellular Fibronectin: Distinct and Independent Functions During Tissue Repair. Fibrogenesis Tissue Repair (2011) 4:21. doi: 10.1186/1755-1536-4-21

83. Löhr M, Trautmann B, Göttler M, Peters S, Zauner I, Maillet B, et al. Human Ductal Adenocarcinomas of the Pancreas Express Extracellular Matrix Proteins. Br J Cancer (1994) 69:144-51. doi: 10.1038/bjc.1994.24

84. Giancotti FG, Ruoslahti E. Integrin Signaling. Science (1999) 285:1028. doi: 10.1126/science.285.5430.1028

85. Zeltz C, Orgel J, Gullberg D. Molecular Composition and Function of Integrin-Based Collagen Glues-Introducing COLINBRIs. Biochim Biophys Acta (BBA) - Gen Subj (2014) 1840:2533-48. doi: 10.1016/ j.bbagen.2013.12.022

86. Miyamoto H, Murakami T, Tsuchida K, Sugino H, Miyake H, Tashiro S. Tumor-Stroma Interaction of Human Pancreatic Cancer: Acquired Resistance to Anticancer Drugs and Proliferation Regulation Is Dependent on Extracellular Matrix Proteins. Pancreas (2004) 28:38-44. doi: 10.1097/ 00006676-200401000-00006

87. Dallas SL, Sivakumar P, Jones CJP, Chen Q, Peters DM, Mosher DF, et al. Fibronectin Regulates Latent Transforming Growth Factor- $\beta$ (Tgf $\beta$ ) by Controlling Matrix Assembly of Latent Tgf $\beta$-Binding Protein-1 *. J Biol Chem (2005) 280:18871-80. doi: 10.1074/jbc.M410762200

88. Arnold SA, Rivera LB, Miller AF, Carbon JG, Dineen SP, Xie Y, et al. Lack of Host SPARC Enhances Vascular Function and Tumor Spread in an Orthotopic Murine Model of Pancreatic Carcinoma. Dis Models Mech (2010) 3:57-72. doi: 10.1242/dmm.003228

89. Egeblad M, Rasch MG, Weaver VM. Dynamic Interplay Between the Collagen Scaffold and Tumor Evolution. Curr Opin Cell Biol (2010) 22:697-706. doi: 10.1016/j.ceb.2010.08.015

90. Nie J, Chang B, Traktuev DO, Sun J, March K, Chan L, et al. IFATS Collection: Combinatorial Peptides Identify Alpha5beta1 Integrin as a Receptor for the Matricellular Protein SPARC on Adipose Stromal Cells. Stem Cells (Dayton Ohio) (2008) 26:2735-45. doi: 10.1634/ stemcells.2008-0212

91. Fraser JRE, Laurent TC, Laurent UBG. Hyaluronan: Its Nature, Distribution, Functions and Turnover. J Internal Med (1997) 242:27-33. doi: 10.1046/ j.1365-2796.1997.00170.x

92. Chauhan VP, Martin JD, Liu H, Lacorre DA, Jain SR, Kozin SV, et al. Angiotensin Inhibition Enhances Drug Delivery and Potentiates Chemotherapy by Decompressing Tumour Blood Vessels. Nat Commun (2013) 4:2516-6. doi: 10.1038/ncomms3516

93. Thompson CB, Shepard HM, Connor PM, Kadhim S, Jiang P, Osgood RJ, et al. Enzymatic Depletion of Tumor Hyaluronan Induces Antitumor Responses in Preclinical Animal Models. Mol Cancer Ther (2010) 9:3052. doi: 10.1158/1535-7163.MCT-10-0470

94. De Oliveira G, Freire PP, Cury SS, De Moraes D, Oliveira JS, Dal-Pai-Silva $\mathrm{M}$, et al. An Integrated Meta-Analysis of Secretome and Proteome Identify Potential Biomarkers of Pancreatic Ductal Adenocarcinoma. Cancers (2020) 12:716. doi: $10.3390 /$ cancers 12030716
95. Biondani G, Zeeberg K, Greco MR, Cannone S, Dando I, Dalla Pozza E, et al. Extracellular Matrix Composition Modulates PDAC Parenchymal and Stem Cell Plasticity and Behavior Through the Secretome. FEBS J (2018) 285:2104-24. doi: 10.1111/febs.14471

96. Apte MV, Pirola RC, Wilson JS. Pancreatic Stellate Cells: A Starring Role in Normal and Diseased Pancreas. Front Physiol (2012) 3:344. doi: 10.3389/ fphys.2012.00344

97. Bachem MG, Schneider E, Groß H, Weidenbach H, Schmid RM, Menke A, et al. Identification, Culture, and Characterization of Pancreatic Stellate Cells in Rats and Humans. Gastroenterology (1998) 115:421-32. doi: 10.1016/ S0016-5085(98)70209-4

98. Bailey JM, Swanson BJ, Hamada T, Eggers JP, Singh PK, Caffery T, et al. Sonic Hedgehog Promotes Desmoplasia in Pancreatic Cancer. Clin Cancer Res (2008) 14:5995-6004. doi: 10.1158/1078-0432.CCR-08-0291

99. Li X, Wang Z, Ma Q, Xu Q, Liu H, Duan W, et al. Sonic Hedgehog Paracrine Signaling Activates Stromal Cells to Promote Perineural Invasion in Pancreatic Cancer. Clin Cancer Res (2014) 20:4326. doi: 10.1158/10780432.CCR-13-3426

100. Duan W, Chen K, Jiang Z, Chen X, Sun L, Li J, et al. Desmoplasia Suppression by Metformin-Mediated AMPK Activation Inhibits Pancreatic Cancer Progression. Cancer Lett (2017) 385:225-33. doi: 10.1016/j.canlet.2016.10.019

101. Shen W, Tao G-Q, Zhang Y, Cai B, Sun J, Tian Z-Q. TGF- $\beta$ in Pancreatic Cancer Initiation and Progression: Two Sides of the Same Coin. Cell bioscience (2017) 7:39-9. doi: 10.1186/s13578-017-0168-0

102. Kato Y, Inoue H, Yoshioka U, Fujiyama Y, Bamba T. Effects of Transforming Growth Factor $\alpha 1$, Interleukin-1 $\beta$, Tumor Necrosis Factor $\alpha$ and PlateletDerived Growth Factor on the Collagen Synthesis and the Proliferation of Periacinal Fibroblastoid Cells Isolated and Cultured From Rat Pancreatic Acini. Pathophysiology (1996) 3:175-9. doi: 10.1016/0928-4680(96)00012-0

103. Shany S, Sigal-Batikoff INA, Lamprecht S. Vitamin D and Myofibroblasts in Fibrosis and Cancer: At Cross-Purposes With TGF- $\beta / S M A D$ Signaling. Anticancer Res (2016) 36:6225. doi: 10.21873/anticanres.11216

104. Paszek MJ, Zahir N, Johnson KR, Lakins JN, Rozenberg GI, Gefen A, et al. Tensional Homeostasis and the Malignant Phenotype. Cancer Cell (2005) 8:241-54. doi: 10.1016/j.ccr.2005.08.010

105. Rice AJ, Cortes E, Lachowski D, Cheung BCH, Karim SA, Morton JP, et al. Matrix Stiffness Induces Epithelial-Mesenchymal Transition and Promotes Chemoresistance in Pancreatic Cancer Cells. Oncogenesis (2017) 6:e352-2. doi: 10.1038/oncsis.2017.54

106. Haage A, Schneider IC. Cellular Contractility and Extracellular Matrix Stiffness Regulate Matrix Metalloproteinase Activity in Pancreatic Cancer Cells. FASEB J (2014) 28:3589-99. doi: 10.1096/fj.13-245613

107. Cox TR, Bird D, Baker A-M, Barker HE, Ho MWY, Lang G, et al. LOXMediated Collagen Crosslinking Is Responsible for Fibrosis-Enhanced Metastasis. Cancer Res (2013) 73:1721-32. doi: 10.1158/0008-5472.CAN12-2233

108. Lee J, Condello S, Yakubov B, Emerson R, Caperell-Grant A, Hitomi K, et al. Tissue Transglutaminase Mediated Tumor-Stroma Interaction Promotes Pancreatic Cancer Progression. Clin Cancer Res (2015) 21:4482-93. doi: 10.1158/1078-0432.CCR-15-0226

109. Verderio EAM, Johnson T, Griffin M. Tissue Transglutaminase in Normal and Abnormal Wound Healing: Review Article. Amino Acids (2004) 26:387404. doi: 10.1007/s00726-004-0094-4

110. Laklai H, Miroshnikova YA, Pickup MW, Collisson EA, Kim GE, Barrett AS, et al. Genotype Tunes Pancreatic Ductal Adenocarcinoma Tissue Tension to Induce Matricellular Fibrosis and Tumor Progression. Nat Med (2016) 22:497-505. doi: 10.1038/nm.4082

111. Dupont S, Morsut L, Aragona M, Enzo E, Giulitti S, Cordenonsi M, et al. Role of YAP/TAZ in Mechanotransduction. Nature (2011) 474:179-83. doi: 10.1038/nature10137

112. Piccolo S, Dupont S, Cordenonsi M. The Biology of YAP/TAZ: Hippo Signaling and Beyond. Physiol Rev (2014) 94:1287-312. doi: 10.1152/ physrev.00005.2014

113. Gruber R, Panayiotou R, Nye E, Spencer-Dene B, Stamp G, Behrens A. YAP1 and TAZ Control Pancreatic Cancer Initiation in Mice by Direct UpRegulation of JAK-STAT3 Signaling. Gastroenterology (2016) 151:526-39. doi: 10.1053/j.gastro.2016.05.006 
114. Li X, Shepard HM, Cowell JA, Zhao C, Osgood RJ, Rosengren S, et al. Parallel Accumulation of Tumor Hyaluronan, Collagen, and Other Drivers of Tumor Progression. Clin Cancer Res (2018) 24:4798-807. doi: 10.1158/10780432.CCR-17-3284

115. Van Cutsem E, Tempero MA, Sigal D, Oh D-Y, Fazio N, Macarulla T, et al. Randomized Phase III Trial of Pegvorhyaluronidase Alfa With NabPaclitaxel Plus Gemcitabine for Patients With Hyaluronan-High Metastatic Pancreatic Adenocarcinoma. J Clin Oncol (2020) 38:3185-94. doi: $10.1200 /$ JCO.20.00590

116. Steele NG, Biffi G, Kemp SB, Zhang Y, Drouillard D, Syu L, et al. Inhibition of Hedgehog Signaling Alters Fibroblast Composition in Pancreatic Cancer. Clin Cancer Res (2021) 27:2023. doi: 10.1158/10780432.CCR-20-3715

117. Vennin C, Chin VT, Warren SC, Lucas MC, Herrmann D, Magenau A, et al. Transient Tissue Priming via ROCK Inhibition Uncouples Pancreatic Cancer Progression, Sensitivity to Chemotherapy, and Metastasis. Sci Transl Med (2017) 9:eaai8504. doi: 10.1126/scitranslmed.aai8504

118. Rath N, Munro J, Cutiongco MF, Jagiełło A, Gadegaard N, Mcgarry L, et al. Rho Kinase Inhibition by AT13148 Blocks Pancreatic Ductal Adenocarcinoma Invasion and Tumor Growth. Cancer Res (2018) 78:3321-36. doi: 10.1158/0008-5472.CAN-17-1339

119. Whatcott CJ, Ng S, Barrett MT, Hostetter G, Von Hoff DD, Han H. Inhibition of ROCK1 Kinase Modulates Both Tumor Cells and Stromal Fibroblasts in Pancreatic Cancer. PloS One (2017) 12:e0183871-e0183871. doi: 10.1371/journal.pone.0183871

120. Vennin C, Rath N, Pajic M, Olson MF, Timpson P. Targeting ROCK Activity to Disrupt and Prime Pancreatic Cancer for Chemotherapy. Small GTPases (2020) 11:45-52. doi: 10.1080/21541248.2017.1345712

121. Mcleod R, Kumar R, Papadatos-Pastos D, Mateo J, Brown JS, Garces AHI, et al. First-In-Human Study of AT13148, a Dual ROCK-AKT Inhibitor in Patients With Solid Tumors. Clin Cancer Res (2020) 26:4777. doi: 10.1158/ 1078-0432.CCR-20-0700

122. Artaza JN, Norris KC. Vitamin D Reduces the Expression of Collagen and Key Profibrotic Factors by Inducing an Antifibrotic Phenotype in Mesenchymal Multipotent Cells. J Endocrinol (2009) 200:207-21. doi: 10.1677/JOE-08-0241

123. Sherman MH, Yu RT, Engle DD, Ding N, Atkins AR, Tiriac H, et al. Vitamin D Receptor-Mediated Stromal Reprogramming Suppresses Pancreatitis and Enhances Pancreatic Cancer Therapy. Cell (2014) 159:80-93. doi: 10.1016/ j.cell.2014.08.007

124. Porter RL, Magnus NKC, Thapar V, Morris R, Szabolcs A, Neyaz A, et al. Epithelial to Mesenchymal Plasticity and Differential Response to Therapies in Pancreatic Ductal Adenocarcinoma. Proc Natl Acad Sci (2019) 116:26835. doi: 10.1073/pnas.1914915116

125. Cheng H, Lu C, Tang R, Pan Y, Bao S, Qiu Y, et al. Ellagic Acid Inhibits the Proliferation of Human Pancreatic Carcinoma PANC-1 Cells In Vitro and In Vivo. Oncotarget (2017) 8:12301-10. doi: 10.18632/oncotarget.14811
126. Gorchs L, Ahmed S, Mayer C, Knauf A, Fernández Moro C, Svensson M, et al. The Vitamin D Analogue Calcipotriol Promotes an Anti-Tumorigenic Phenotype of Human Pancreatic CAFs But Reduces T Cell Mediated Immunity. Sci Rep (2020) 10:17444. doi: 10.1038/s41598-020-74368-3

127. Ciardiello D, Elez E, Tabernero J, Seoane J. Clinical Development of Therapies Targeting Tgf $\beta$ : Current Knowledge and Future Perspectives. Ann Oncol (2020) 31:1336-49. doi: 10.1016/j.annonc.2020.07.009

128. Greco R, Qu H, Qu H, Theilhaber J, Shapiro G, Gregory R, et al. Pan-Tgf Inhibition by SAR439459 Relieves Immunosuppression and Improves Antitumor Efficacy of PD-1 Blockade. Oncoimmunology (2020) 9:1811605-1811605. doi: 10.1080/2162402X.2020.1811605

129. Moffitt RA, Marayati R, Flate EL, Volmar KE, Loeza SGH, Hoadley KA, et al. Virtual Microdissection Identifies Distinct Tumor- and Stroma-Specific Subtypes of Pancreatic Ductal Adenocarcinoma. Nat Genet (2015) 47:1168-78. doi: 10.1038/ng.3398

130. Collisson EA, Bailey P, Chang DK, Biankin AV. Molecular Subtypes of Pancreatic Cancer. Nat Rev Gastroenterol Hepatol (2019) 16:207-20. doi: 10.1038/s41575-019-0109-y

131. Elyada E, Bolisetty M, Laise P, Flynn WF, Courtois ET, Burkhart RA, et al. Cross-Species Single-Cell Analysis of Pancreatic Ductal Adenocarcinoma Reveals Antigen-Presenting Cancer-Associated Fibroblasts. Cancer Discovery (2019) 9:1102-23. doi: 10.1158/2159-8290.CD-19-0094

132. Daemen A, Peterson D, Sahu N, Mccord R, Du X, Liu B, et al. Metabolite Profiling Stratifies Pancreatic Ductal Adenocarcinomas Into Subtypes With Distinct Sensitivities to Metabolic Inhibitors. Proc Natl Acad Sci (2015) 112: E4410. doi: 10.1073/pnas.1501605112

133. Ogawa Y, Masugi Y, Abe T, Yamazaki K, Ueno A, Fujii-Nishimura Y, et al. Three Distinct Stroma Types in Human Pancreatic Cancer Identified by Image Analysis of Fibroblast Subpopulations and Collagen. Clin Cancer Res (2021) 27:107. doi: 10.1158/1078-0432.CCR-20-2298

Conflict of Interest: The authors declare that the research was conducted in the absence of any commercial or financial relationships that could be construed as a potential conflict of interest.

Publisher's Note: All claims expressed in this article are solely those of the authors and do not necessarily represent those of their affiliated organizations, or those of the publisher, the editors and the reviewers. Any product that may be evaluated in this article, or claim that may be made by its manufacturer, is not guaranteed or endorsed by the publisher.

Copyright (c) 2021 Perez, Kearney and Yeh. This is an open-access article distributed under the terms of the Creative Commons Attribution License (CC BY). The use, distribution or reproduction in other forums is permitted, provided the original author(s) and the copyright owner(s) are credited and that the original publication in this journal is cited, in accordance with accepted academic practice. No use, distribution or reproduction is permitted which does not comply with these terms. 